\title{
Acne Supplements Sold Online
}

\author{
Emily Burns ${ }^{1}$, Milbrey Parke ${ }^{1}$, Ariadna Perez-Sanchez ${ }^{2}$, Dina Zamil ${ }^{1}$, Rajani Katta ${ }^{3}$
}

1 Baylor College of Medicine, Houston, TX, USA

2 Department of Internal Medicine, University of Texas Health Science Center at San Antonio, San Antonio, TX, USA

3 Department of Dermatology, McGovern Medical School at University of Texas Health Science Center at Houston, Houston, TX, USA

Key words: acne supplement, dietary supplement, diet, nutrition, safety

Citation: Burns E, Parke M, Perez-Sanchez A, Zamil D, Rajani K. Acne supplements sold online.

Dermatol Pract Concept. 2022; 12(1): e2022029. DOI: https://doi.org/10.5826/dpc.1201a29

Accepted: August 2, 2021; Published: January 2022

Copyright: $\odot 2022$ Burns et al. This is an open-access article distributed under the terms of the Creative Commons

Attribution-NonCommercial License (BY-NC-4.0), https://creativecommons.org/licenses/by-nc/4.0/, which permits unrestricted noncommercial use, distribution, and reproduction in any medium, provided the original authors and source are credited.

Funding: None.

Competing interests: None.

Authorship: All authors have contributed significantly to this publication.

Corresponding author: Rajani Katta, MD, Department of Dermatology, McGovern Medical School at University of Texas Health Science Center at Houston, Houston, TX, USA. E-mail: info@kattamd.com

\footnotetext{
ABSTRACT Introduction: As no centralized database of acne supplements is available, we aimed to provide an overview of these products, with a focus on safety.

Objectives: The objectives of this study were to document the number, formulation, contents, and marketing strategies utilized by acne supplements sold online.

Methods: An online search was conducted between March and May 2020. Products were included in the study if they used the terms: "whitehead", "blackhead", or "acne". Data were extracted from the website, box, and Supplement Facts label.

Results: 49 products were identified, which contained 146 unique ingredients. These included vitamins, minerals, food extracts, botanical extracts, amino acids, animal products, and distinct microbial strains. Few $(4.1 \%)$ products were tested by third parties.

Conclusions: This survey of acne supplements available online raised concerns regarding lack of warning labels, teratogenicity, exceedingly large levels of vitamins and minerals, and lack of thirdparty testing. Given the limited regulation and oversight of dietary supplements, it is imperative that physicians educate patients on the potential risks of these products.
} 


\section{Introduction}

\section{Dietary Supplements in the US}

Dietary supplements are becoming increasingly popular in the U.S. Studies estimate that approximately $50 \%$ of the US population consumes some form of dietary supplement [1]. The number of American people who consume acne supplements is unknown.

\section{The Role of Dietary Supplements in Acne}

Acne affects up to 50 million American residents each year, and its prevalence has been reported to be as high as $85 \%$ among people aged 12-24 years [2,3]. The role of diet and dietary supplements in the development and treatment of acne is an evolving field of study. A recent systematic review including 53 articles revealed that acne-promoting factors include high glycemic index food, dairy, fatty food, and chocolate. Acne-protective factors include fruits and vegetables. The possible varying degrees of acne-promotion of specific subtypes of these foods (eg full-fat milk vs. low-fat milk) is unknown [4].

High doses of oral zinc have been shown to reduce severe and inflammatory acne in double-blind randomized control trials (RCTs) [5,6]. Successful trials have used different dosages and forms of zinc as well as zinc in combination with other ingredients [7]. Therefore, future research is needed to elucidate the best zinc dose and form associated with improved acne outcomes.

Other vitamins and minerals have been studied, but double-blind RCTs are lacking [5,8]. Low selenium levels have been documented in patients with acne; however, the clinical significance of low selenium and acne development is unknown [5,9]. A cross-sectional study comparing blood levels of vitamins $\mathrm{A}$ and $\mathrm{E}$ in 100 patients with acne and 100 patients without acne showed that subjects with acne had significantly lower plasma concentrations of these vitamins compared to the control subjects $[5,10]$.

Other naturally occurring compounds have been evaluated in animal and in vitro studies but human studies are lacking. These compounds have exhibited antioxidant and antibacterial properties, such as (--) epigallocatechin-3-gallate from green tea and nobiletin from Citrus depressa (a green citrus fruit native from Taiwan and Japan) [5,11,12]. In hamsters, these compounds have been shown to reduce sebum production and inhibit cell proliferation of sebaceous glands respectively.

The flavonoids kaempferon and quercetin from the Inpatiens balsamina flower as well as resveratrol found in several other plants have been shown to possess antibacterial properties against Propionibacterium acnes in vitro $[5,13,14]$.

\section{Objectives}

The objective of this study was to document the number, formulation, contents, and marketing strategies utilized by acne supplements sold online.

\section{Methods}

We conducted a search of acne supplements sold online between March 2020 and May 2020 using Google, Amazon, Twitter, and Instagram. Acne supplements were defined as those featuring the words "whitehead", "blackhead", and/or "acne" (Figure 1). Data were extracted from the Supplement Facts label, manufacturer website, and/or third-party seller website for each product. Third-party sellers include Amazon and online supplement retailers.

\section{Results}

\section{Ingredients}

Forty-nine products were identified, which in total contained 146 unique ingredients including vitamins, minerals, food extracts, botanical extracts, amino acids, animal products, and distinct microbial strains (Table 1). Products contained an average of 3.18 vitamins, and the most common vitamins included in descending order were vitamins A, E, B3, B5, and B6 (Table 2). Products contained an average of 2.6 minerals, and the most common minerals included were zinc and selenium (Table 3). Many products contained supraphysiologic doses of vitamins and minerals (Table 4), (Figure 2).

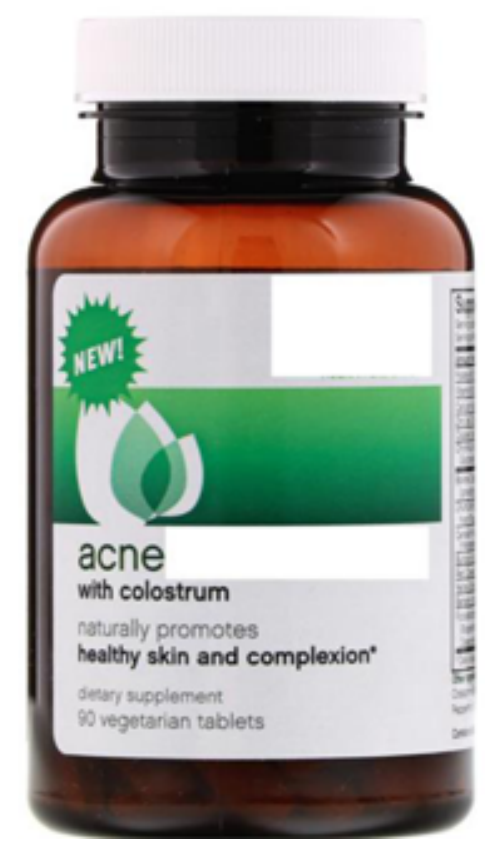

Figure 1. Example of product image of an acne supplement sold online 
Table 1. List of Selected Ingredients

\begin{tabular}{|l|}
\hline Methylsulfonylmethane (MSM) \\
\hline Coenzyme Q10 (CoQ10) \\
\hline Horsetail powder \\
\hline Pepper extract \\
\hline Grape seed extract \\
\hline Turmeric \\
\hline Diindolylmethane (DIM) \\
\hline Licorice root extract \\
\hline Bovine Adrenal Powder \\
\hline Bacteriophages \\
\hline Bovine Colostrum \\
\hline
\end{tabular}

Table 2. Vitamins Included in Acne Supplements Sold Online

\begin{tabular}{|l|c|}
\hline \multicolumn{1}{|c|}{ Vitamin } & \% of Products \\
\hline A & 53.1 \\
\hline B3 (niacin) & 34.7 \\
\hline B5 (pantothenic acid) & 34.7 \\
\hline B6 (pyridoxine) & 34.7 \\
\hline E (tocopherol) & 34.7 \\
\hline No Vitamins & 32.7 \\
\hline C & 30.6 \\
\hline B7 (biotin) & 24.5 \\
\hline B2 (riboflavin) & 16.3 \\
\hline B12 (cobalamin) & 14.3 \\
\hline D & 14.3 \\
\hline B1 (thiamine) & 12.2 \\
\hline B9 (folate) & 10.2 \\
\hline K & 4 \\
\hline
\end{tabular}

Table 3. Mineral Content ( $\%$ ) of Acne Supplements Sold Online

\begin{tabular}{|l|c|}
\hline \multicolumn{1}{|c|}{ Mineral } & \% of Products \\
\hline Zinc & 65.3 \\
\hline Selenium & 40.8 \\
\hline Chromium & 32.7 \\
\hline Copper & 28.6 \\
\hline Magnesium & 28.6 \\
\hline No Minerals & 26.5 \\
\hline Calcium & 14.3 \\
\hline Manganese & 12.2 \\
\hline Sodium & 8.2 \\
\hline Potassium & 8.2 \\
\hline Iron & 6.1 \\
\hline Sulfur & 6.1 \\
\hline Iodine & 4.1 \\
\hline Phosphorus & 4.1 \\
\hline
\end{tabular}

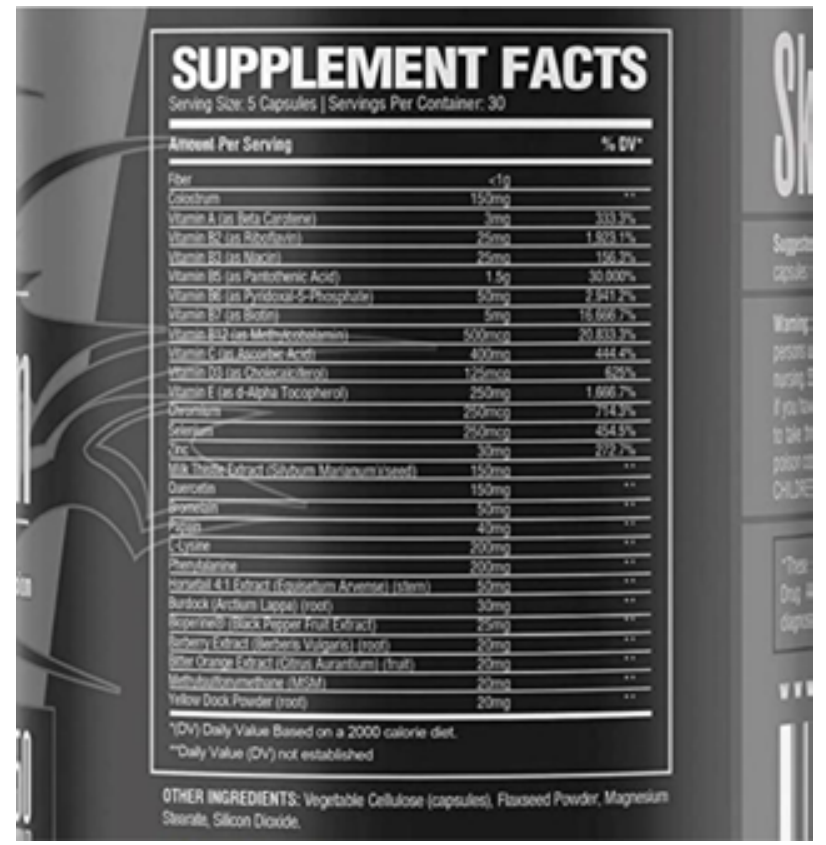

Figure 2. Example of Supplement Facts label image from an acne supplement sold online

Table 4. High Doses of Vitamins and Minerals from Selected Acne Supplements

\begin{tabular}{|l|c|c|}
\multicolumn{1}{|c|}{ Nutrient } & Labeled Dose & $\begin{array}{c}\text { \% of Daily } \\
\text { Values }\end{array}$ \\
\hline Vitamin A & $21,000 \mathrm{mcg}$ RAE & $2,333 \%$ \\
\hline $\begin{array}{l}\text { Vitamin B2 } \\
\text { (Riboflavin) }\end{array}$ & $25 \mathrm{mg}$ & $1,923 \%$ \\
\hline $\begin{array}{l}\text { Vitamin B3 } \\
\text { (Niacin) }\end{array}$ & $500 \mathrm{mg}$ & $2,500 \%$ \\
\hline $\begin{array}{l}\text { Vitamin B5 } \\
\text { (Pantothenic Acid) }\end{array}$ & $350 \mathrm{mg}$ & $3,500 \%$ \\
\hline Vitamin B6 & $50 \mathrm{mg}$ & $2,500 \%$ \\
\hline $\begin{array}{l}\text { Vitamin B7 } \\
\text { (Biotin) }\end{array}$ & $500 \mathrm{mcg}$ & $2,500 \%$ \\
\hline Vitamin B12 & $280 \mathrm{mg}$ & $20,833 \%$ \\
\hline Vitamin C & $50 \mathrm{mg}$ & $367 \%$ \\
\hline Chromium & & $333 \%$ \\
\hline Zinc & & \\
\hline
\end{tabular}

Many products contained botanical and food extracts. The most common extracts included were methylsulfonylmethane (MSM, 20\%), coenzyme Q10 (CoQ10,13\%), horsetail powder $(10 \%)$, pepper extract $(10 \%)$, grape seed extract $(8 \%)$, turmeric $(8 \%)$, diindolylmethane (DIM, 7\%), and licorice root extract $(6 \%)$.

\section{Formulation}

Capsules were the most common formulation, followed by tablets and gummies. 


\section{Dosing}

$47.9 \%$ of products did not provide clear labeling for total daily dose. For example, the Supplement Facts box included the dose for one capsule, but the recommended dose is two capsules.

\section{Pricing}

Pricing varied from $\$ 10-204$ per month supply. The median price per month was $\$ 31$.

\section{Third-Party Seals of Approval}

Approximately $4 \%$ of products displayed seals of approval from third-party testing centers recognized by the US Office of Dietary Supplements.

\section{Marketing and Claims}

The most common marketing claims included gluten free $(67 \%)$, vegan or vegetarian $(45 \%)$, made in the USA $(43 \%)$, natural $(43 \%)$, hormonal balance or regulates hormones $(43 \%)$, detoxify $(41 \%)$, inflammation (39\%), antioxidant $(37 \%)$, proprietary blend $(26 \%)$, and cruelty free $(20 \%)$. Most (55.1\%) products used the terms "research" or "clinical study" in the marketing materials. Some $(8.2 \%)$ products cited a clinical study. Most $(55.0 \%)$ of products had an auto-delivery or subscription option available upon checkout. Most (55.1\%) of products had a coupon available upon checkout. Other marketing techniques included before-andafter photographs $(51.1 \%)$ and video testimonials $(12.2 \%)$. Most (83.7\%) supplements were reviewed on Amazon.

\section{Labeling}

Some $(20.8 \%)$ products had different information provided by multiple sources. In these instances, labels provided by Amazon sellers conflicted with third party sellers and/or manufacturers. For the purposes of the data collection of this study, the label from the manufacturer website was used. Supplement manufacturers are required by law to include the phrase "This statement has not been evaluated by the FDA. This product is not intended to diagnose, treat, cure, or prevent any disease" on the bottle if a structure/function claim is made. $12.2 \%$ of products did not have this phrase clearly visible online. A $53.1 \%$ of products did not list a phrase containing or similar to "Consult your doctor or health care practitioner before use" and $30.6 \%$ of products failed to include any type of pregnancy warning.

\section{Conclusions}

Acne supplement manufacturers use a wide variety of ingredients and health claims. There is little consensus among these products regarding the number or dosing of vitamins, minerals, extracts, and other ingredients. They are sold on manufacturer websites and third-party websites. This study raises concerns about lack of US Food and Drug Administration (FDA) oversight, lack of third-party testing, teratogenicity potential, marketing practices, untested ingredient profile, supraphysiologic vitamin dosing, vulnerable patient population, and consumer confusion.

The US FDA regulates supplements as foods, not drugs [15]. There is no requirement to prove safety or efficacy prior to sale, and there is no limit on dosages of vitamins or minerals, even for those with defined tolerable upper limits. There is also no requirement to test or document interactions between ingredients and/or other medications [16].

Although the US FDA requires that supplements sold in stores display the Supplement Facts label, this requirement does not apply to supplements sold online. On some websites, including Amazon and other third-party sellers, this label was not visible.

The FDA has issued Good Manufacturing Practices (GMPs), which are a set of guidelines for safe manufacturing of dietary supplements. The FDA expects manufacturers to comply with GMPs but does not regularly investigate for compliance with these rules [15].

In terms of quality testing, only $4.1 \%$ of products in our sample were tested by third-party companies recognized by the Office of Dietary Supplements, including the US Pharmacopeia, National Sanitation Foundation, and Consumer Lab. Without US FDA testing or third-party testing, consumers must rely only on the companies themselves to ensure the safety, purity, and lack of contamination of these products.

To date, there is little data about the quality and safety of acne supplements sold online. Ayurvedic medicines sold online have been documented to contain heavy metals including lead, mercury, and arsenic [17]. In 2015, the New York State attorney general's office accused four national retailers of selling dietary supplements containing unadvertised, potentially allergenic ingredients. Many products did not contain the advertised herbal ingredients, and some contained allergenic components, such as wheat, while advertising that the product was "gluten-free" [18].

With regards to teratogenicity, prescription medications require a package insert with pregnancy warning categories, which indicate risk to the developing fetus. No such notification is required for supplements, even for compounds that pose a known teratogenic risk. Consumers of child-bearing potential should exercise caution when consuming acne supplements, as some of these products may pose a risk to the developing fetus.

High dietary doses of preformed vitamin A (> 10,000 IU) during early pregnancy are associated with neural crest defects such as cleft lip, ventricular septal defect, transposition of the great vessels, hydrocephalus, and craniosynostosis [19]. 
In our sample, $6.1 \%$ of acne supplements sold online included potentially teratogenic levels of vitamin A. The teratogenic potential of another $8 \%$ of products containing vitamin $\mathrm{A}$ could not be determined because the products did not specify the form of vitamin A [20].

In terms of marketing strategies, most products $(55.1 \%)$ included the terms "research" or "clinical study" on the labeling, and some products cited the research used to support the claim. Two studies cited by a product were evaluating magnesium, B6, and a plant extract (Vitex agnes cactus) for use in premenstrual syndrome [21,22]. These studies did not evaluate use of these components for acne. One website referenced three articles that were not found online and could not be substantiated. During the editing process, these articles were removed from the product's website. Another article did not appear in a PubMed-indexed journal [23].

Our survey documented a wide variety of ingredients contained in these products, including many ingredients that have not been tested in human acne studies. The most included ingredients outside of vitamins and minerals were MSM, CoQ10, horsetail powder, pepper extract, grape seed extract, turmeric, DIM, and licorice root extract. The topical application of grape seed extract is associated with decreased sebum content in human skin [24]; however, we were unable to locate research on oral grapeseed extract intake or the other listed compounds in acne.

Interestingly, the few plant compounds (kaempferon, querceptin, green tea extract and nobiletin) that have been studied in hamsters and in vitro were not the most commonly used extracts. Some unique and unexpected ingredients included bovine adrenal powder, a proprietary enzyme blend including digestive enzymes, bacteriophages intended to affect gut bacteria, and bovine colostrum, intended to improve natural defenses.

High-dose vitamins and minerals were used in multiple products and represent another area of concern. Vitamins A, B2, B3, B5, B6, B7, B12, C as well as chromium and zinc were included in very high doses. As zinc has been shown to reduce acne, it was unsurprising that zinc was the most commonly used mineral (65\%) [6].

Supraphysiologic doses of vitamins and minerals included in dietary supplements have been linked to multiple side effects [25]. For example, vitamins B6 and B12 have been associated with a worsening of acne in some reports [26]. Surprisingly, products in our sample included both of these ingredients at high doses: vitamin B6 at 2,500\% of Recommended Dietary Allowance (RDA) and vitamin B12 at $20,833 \%$ of RDA.

As this analysis focused on products sold online, it highlights dangers posed to a vulnerable pediatric population. Many patients suffering from acne are minors. Anyone, including children, can order acne supplements online. Parents and pediatricians should be wary of these products, as they are readily available online.

Finally, of significant concern is that approximately 1 in 5 $(20.8 \%)$ supplements sold in multiple outlets (manufacturer, third-party, Amazon) displayed varying doses of ingredients. It is unclear which label consumers should use to evaluate the dose and ingredients included in the supplement.

\section{Limitations}

As our study was designed only to investigate products sold online, this represents a limited sample of acne supplements. Further research should evaluate products sold in stores. In addition, the authors could not find any PubMed indexed studies evaluating the components of these products using laboratory testing.

Dietary supplements marketed for acne include supraphysiologic levels of vitamins and minerals as well as food extracts, botanical extracts, amino acids, animal products, and microbes. These products do not require US FDA approval and thus do not undergo the same rigorous safety and efficacy testing as pharmaceuticals; however, most products include the term "research" or "clinical study" on their label. Few products undergo testing by third parties, although they can be pharmacologically active and can be linked to adverse effects. Many of the ingredients included in acne supplements have not undergone RCTs to evaluate their efficacy, and high doses of vitamin A may be associated with birth defects in pregnant patients.

As the US FDA does not routinely monitor supplements sold in stores or online, consumers and physicians reporting is vital for monitoring adverse events. The US FDA has an online Safety Reporting portal, which streamlines the process of reporting product safety issues. The portal may be found here: https://www.safetyreporting.hhs.gov/SRP2/en/Home. aspx?sid=0506bbbe-42e5-40f9-a58b-742b04d74295

\section{References}

1. Chen F, Du M, Blumberg JB, et al. Association Between Dietary Supplement Use, Nutrient Intake, and Mortality Among US Adults: A Cohort Study. Ann Intern Med. 2019;170(9):604613. DOI: 10.7326/M18-2478. PMID: 30959527; PMCID: PMC6736694.

2. Bickers DR, Lim HW, Margolis D, et al. The burden of skin diseases: 2004. J Am Acad Dermatol. 2006;55:490-500. DOI: 10.1016/j.jaad.2006.05.048. PMID: 16908356.

3. White GM. Recent findings in the epidemiologic evidence, classification, and subtypes of acne vulgaris. J Am Acad Dermatol. 1998;39:S34-37. DOI: 10.1016/S0190-9622(98)70442-6. PMID: 9703121.

4. Dall'Oglio F, Nasca MR, Fiorentini F, Micali G. Diet and acne: review of the evidence from 2009 to 2020. Int J Dermatol. 2021;60(6):672-685. DOI: 10.1111/ijd.15390. PMID: 33462816. 
5. Bowe WP, Joshi SS, Shalita AR. Diet and acne. J Am Acad Dermatol. 2010; 63(1):124-141. DOI: 10.1016/j.jaad.2009.07.043. PMID: 20338665.

6. Dreno B, Moyse D, Alirezai M, et al. Multicenter randomized comparative double-blind controlled clinical trial of the safety and efficacy of zinc gluconate versus minocycline hydrochloride in the treatment of inflammatory acne vulgaris. Dermatol Basel Switz. 2001;203:135-140. DOI: 10.1159/000051728. PMID: 11586012 .

7. Katta R, Kramer MJ. Skin and Diet: An Update on the Role of Dietary Change as a Treatment Strategy for Skin Disease. Skin Ther Lett. 2018;23:1-5. PMID: 29357214.

8. Michaëlsson G, Edqvist LE. Erythrocyte glutathione peroxidase activity in acne vulgaris and the effect of selenium and vitamin E treatment. Acta Derm Venereol. 1984;64:9-14. PMID: 6203294.

9. Michaëlsson G. Decreased concentration of selenium in whole blood and plasma in acne vulgaris. Acta Derm Venereol. 1990;70:92. PMID: 1967890.

10. El-Akawi Z, Abdel-Latif N, Abdul-Razzak K. Does the plasma level of vitamins A and E affect acne condition? Clin Exp Dermatol.2006;31:430-434. DOI: 10.1111/j.1365-2230.2006.02106.x. PMID: 16681594.

11. Liao $S$. The medicinal action of androgens and green tea epigallocatechin gallate. Hong Kong Med J Xianggang Yi Xue Za Zhi. 2001;7:369-374. PMID: 11773671.

12. Sato T, Takahashi A, Kojima M, Akimoto N, Yano M, Ito A. A citrus polymethoxy flavonoid, nobiletin inhibits sebum production and sebocyte proliferation, and augments sebum excretion in hamsters. J Invest Dermatol. 2007;127(12):2740-8. DOI: 10.1038/sj.jid.5700927. PMID: 17597820.

13. Docherty JJ, McEwen HA, Sweet TJ, Bailey E, Booth TD. Resveratrol inhibition of Propionibacterium acnes. J Antimicrob Chemother. 2007;59:1182-1184. DOI: 10.1093/jac/dkm099. [PMID: 17449884.

14. Lim Y-H, Kim I-H, Seo J-J. In vitro activity of kaempferol isolated from the Impatiens balsamina alone and in combination with erythromycin or clindamycin against Propionibacterium acnes. J Microbiol Seoul Korea. 2007;45:473-477. PMID: 17978809.

15. Frequently Asked Questions. National Institutes of Health: Office of Dietary Supplements. Updated February 5, 2021. Available from: https://ods.od.nih.gov/HealthInformation/ODS_Frequently_Asked_Questions.aspx. Accessed April 6, 2021.

16. Dietary Supplements: What You Need to Know. National Institutes of Health: Office of Dietary Supplements. Updated Septem- ber 3, 2020. Available from: https://ods.od.nih.gov/factsheets/ WYNTK-Consumer/. Accessed April 6, 2021.

17. Saper RB, Phillips RS, Sehgal A, et al. Lead, mercury, and arsenic in US- and Indian-manufactured Ayurvedic medicines sold via the Internet. JAMA. 2008;300:915-923 DOI: 10.1001/ jama.300.8.915. PMID: 18728265; PMCID: PMC2755247.

18. O'Connor A. New York Attorney General Targets Supplements at Major Retailers. N Y Times. 2015. Available from: https://well. blogs.nytimes.com/2015/02/03/new-york-attorney-general-targets-supplements-at-major-retailers/.

19. Rothman KJ, Moore LL, Singer MR, Nguyen US, Mannino S, Milunsky A. Teratogenicity of high vitamin A intake. N Engl J Med. 1995;333(21):1369-7133. DOI: 10.1056/ NEJM199511233332101. PMID: 7477116.

20. Zamil D, Burns E, Perez-Sanchez A, Parke M, Katta R. Risk of Birth Defects From Vitamin A “Acne Supplements” Sold Online. Dermatol Pract Concept. 2021;11(3):e2021075. DOI: 10.5826/ dpc.1103a75. PMID: 34123566; PMCID: PMC8172008.

21. Fathizadeh N, Ebrahimi E, Valiani M, Tavakoli N, Yar MH. Evaluating the effect of magnesium and magnesium plus vitamin B6 supplement on the severity of premenstrual syndrome. Iran J Nurs Midwifery Res. 2010;15:401-405. PMID: 22069417. PMCID: PMC3208934.

22. Schellenberg R, Zimmermann C, Drewe J, Hoexter G, Zahner C. Dose-dependent efficacy of the Vitex agnus castus extract Ze 440 in patients suffering from premenstrual syndrome. Phytomedicine. 2012;19:1325-31. DOI: 10.1016/j.phymed.2012.08.006. PMID: 23022391.

23. Leung LH. A Stone that Kills two Birds: How Pantothenic Acid Unveils the Mysteries of Acne Vulgaris and Obesity. Journal of Orthomolecular Medicine. 1997; 12(2). Accessed July 2021. http:// orthomolecular.org/library/jom/1997/articles/1997-v12n02-p099. shtml

24. Sharif A, Akhtar N, Khan MS, et al. Formulation and evaluation on human skin of a water-in-oil emulsion containing Muscat hamburg black grape seed extract. Int J Cosmet Sci. 2015;37:253-258. DOI: 10.1111/ics.12184. PMID: 25402429.

25. Burns EK, Perez-Sanchez A, Katta R. Risks of Skin, Hair, and Nail Supplements. Dermatol Pract Concept. 2020;10:e2020089. DOI: $10.5826 / \mathrm{dpc} .1004 \mathrm{a} 89$. PMID: 33150030. PMCID: PMC7588165.

26. Zamil DH, Perez-Sanchez A, Katta R. Acne related to dietary supplements. Dermatol Online J. 2020; 26(8):13030/qt9rp7t2p2. PMID: 32941710. 